\title{
Front Matter: Volume 7840
}

, "Front Matter: Volume 7840," Proc. SPIE 7840, Sixth International Symposium on Digital Earth: Models, Algorithms, and Virtual Reality, 784001 (8 November 2010); doi: 10.1117/12.881075

SPIE Event: The Sixth International Symposium on Digital Earth, 2009, Beijing, China 


\section{PROCEEDINGS OF SPIE}

\section{Sixth International Symposium on Digital Earth: Models, Algorithms, and Virtual Reality}

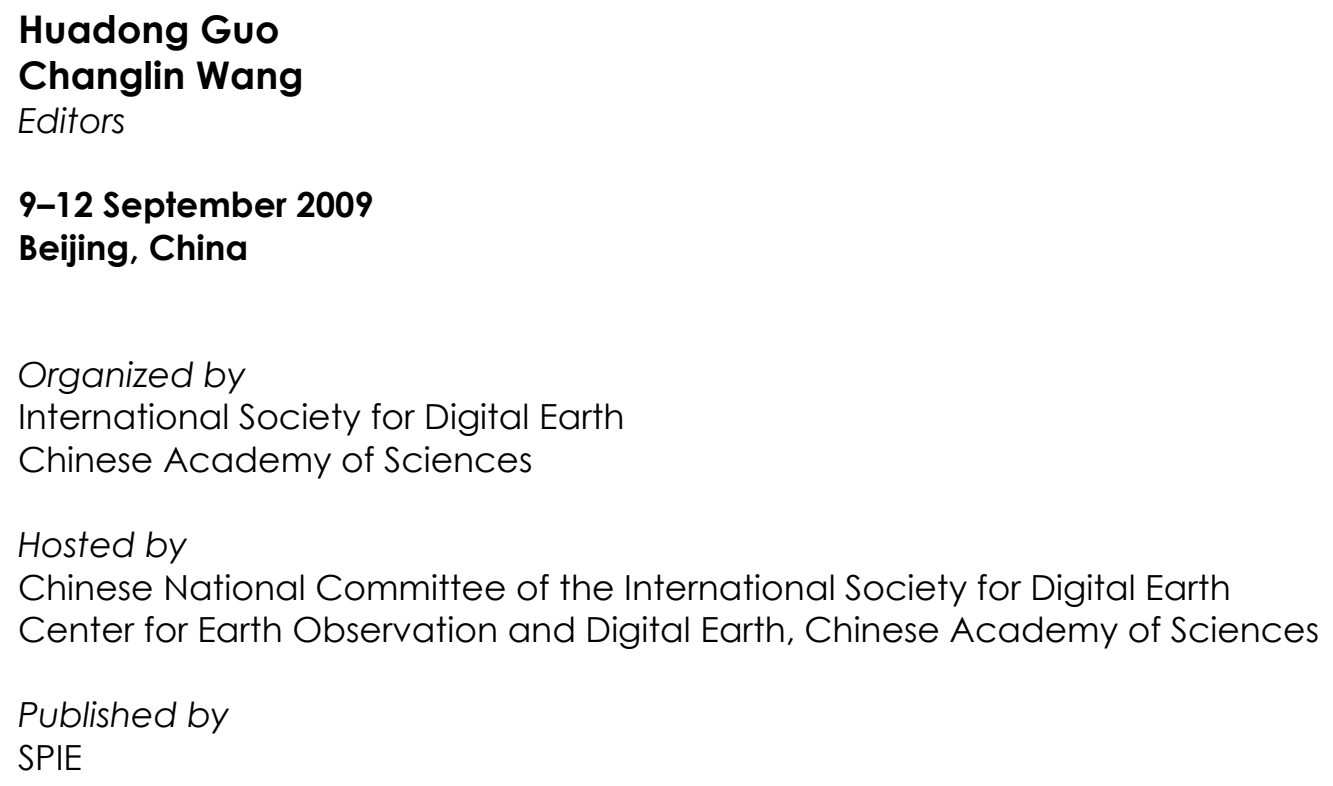


The papers included in this volume were part of the technical conference cited on the cover and title page. Papers were selected and subject to review by the editors and conference program committee. Some conference presentations may not be available for publication. The papers published in these proceedings reflect the work and thoughts of the authors and are published herein as submitted. The publisher is not responsible for the validity of the information or for any outcomes resulting from reliance thereon.

Please use the following format to cite material from this book:

Author(s), "Title of Paper," in Sixth International Symposium on Digital Earth: Models, Algorithms, and Virtual Reality, edited by Huadong Guo, Changlin Wang, Proceedings of SPIE Vol. 7840 (SPIE, Bellingham, WA, 2010) Article CID Number.

ISSN 0277-786X

ISBN 9780819483638

Published by

SPIE

P.O. Box 10, Bellingham, Washington 98227-0010 USA

Telephone +1 3606763290 (Pacific Time) · Fax +1 3606471445

SPIE.org

Copyright (C) 2010, Society of Photo-Optical Instrumentation Engineers

Copying of material in this book for internal or personal use, or for the internal or personal use of specific clients, beyond the fair use provisions granted by the U.S. Copyright Law is authorized by SPIE subject to payment of copying fees. The Transactional Reporting Service base fee for this volume is $\$ 18.00$ per article (or portion thereof), which should be paid directly to the Copyright Clearance Center (CCC), 222 Rosewood Drive, Danvers, MA 01923. Payment may also be made electronically through CCC Online at copyright.com. Other copying for republication, resale, advertising or promotion, or any form of systematic or multiple reproduction of any material in this book is prohibited except with permission in writing from the publisher. The CCC fee code is 0277-786X/10/\$18.00.

Printed in the United States of America.

Publication of record for individual papers is online in the SPIE Digital Library.

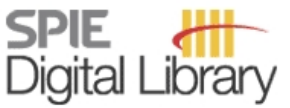

SPIEDigitalLibrary.org

Paper Numbering: Proceedings of SPIE follow an e-First publication model, with papers published first online and then in print and on CD-ROM. Papers are published as they are submitted and meet publication criteria. A unique, consistent, permanent citation identifier (CID) number is assigned to each article at the time of the first publication. Utilization of CIDs allows articles to be fully citable as soon they are published online, and connects the same identifier to all online, print, and electronic versions of the publication. SPIE uses a six-digit CID article numbering system in which:

- The first four digits correspond to the SPIE volume number.

- The last two digits indicate publication order within the volume using a Base 36 numbering system employing both numerals and letters. These two-number sets start with 00, 01, 02, 03, 04, $05,06,07,08,09,0 A, 0 B \ldots 0 Z$, followed by 10-1Z, 20-2Z, etc.

The CID number appears on each page of the manuscript. The complete citation is used on the first page, and an abbreviated version on subsequent pages. Numbers in the index correspond to the last two digits of the six-digit CID number. 


\title{
Contents
}

\author{
xi \\ Organizing Structure of the $6^{\text {th }}$ International Symposium on Digital Earth \\ xiii Conference Committees \\ xxi Introduction \\ xxv Opening Address: Jointly Build the Digital Earth and Bring Benefit to Mankind \\ xxix Opening Address: Create a Bright Future for Digital Earth \\ xxxiii 2009 Beijing Declaration on Digital Earth \\ xxxvii 1999 Beijing Declaration on Digital Earth
}

\section{DIGITAL EARTH FRAMEWORKS, MODELS, AND SPATIAL DATA INFRASTRUCTURE}

784002 Methods of data organization in geo-spatial framework of Digital Earth [7840-01]

H. Chen, Nanjing Forestry Univ. (China); R. Qiu, Nanjing Communication Polytechnic (China)

784003 A new Digital Earth reference model: spheroid-based 3D grid for Earth system (3DGES) [7840-02]

L. WU, J. YU, Beijing Normal Univ. (China)

784004 Digital Earth, a new approach for geoconservation: case study of Hexigten Global Geopark, Inner Mongolia [7840-03]

S. Liu, M. Tian, W. Shi, China Univ. of Geosciences (China)

784005 Super-resolution rendering for Digital Earth applications [7840-04]

M. Li, Univ. of Electronic Science and Technology of China (China) and Guilin Airforce Academy (China); S. Li, Univ. of Electronic Science and Technology of China (China); X. Liu, Univ. of Electronic Science and Technology of China (China) and SiChuan Univ. Of Science and Engineering (China); F. Wang, Univ. of Electronic Science and Technology of China (China); H. Jin, Guilin Airforce Academy (China)

784006 An address geocoding method for improving rural spatial information infrastructure [7840-05]

Y. Pan, B. Chen, Z. LU, S. Li, National Engineering Research Ctr. for Information Technology in Agriculture (China); J. Zhang, Information Ctr. of the Minister of Land and Resources (China); Y. Zhou, National Engineering Research Ctr. for Information Technology in Agriculture (China)

784007 Study on Global GIS architecture and its key technologies [7840-06]

C. Cheng, L. Guan, X. Lv, Peking Univ. (China) 
784008 Model constructing for digital basin information sharing [7840-07]

H. XU, D. Bu, X. Fang, Z. Liu, Hohai Univ. (China)

784009 The research and development of Central Asia geo-science data sharing portal based on the spatial information technology [7840-08]

X. Wang, J. Bi, Ctr. for Earth Observation and Digital Earth, CAS (China)

7840 OA Research on the conceptual model of spatial data infrastructure for natural disaster management [7840-09]

Y. Tu, Q. Li, X. Mao, Peking Univ (China)

7840 OB Multi-resolution visualized model of the global terrain based on DQG [7840-10]

Y. Gao, X. Zhao, D. Fan, J. Fan, China Univ. of Mining and Technology (China)

7840 OC A spatio-temporal data model for administrative division place names: a case study of Xiamen [7840-11]

L. Yang, G. Lin, A. Chen, Y. Chen, X. Wen, Fujian Normal Univ. (China)

7840 OD Study on the monitoring model of soil moisture for Aeolian desertification using MODIS image data [7840-12]

A. Huo, Chang'an Univ. (China) and Northwest Agriculture \& Forestry Univ. (China); Z. Sun, College of Henan Medical for Staff and Workers (China); H. Li, Northwest Agriculture \& Forestry Univ. (China); X. Hou, Baoji Univ. of Arts and Sciences (China); G. Zhang, Northwest Agriculture \& Forestry Univ. (China)

7840 OE High resolution Crop Surface Models (CSM) and Crop Volume Models (CVM) on field level by terrestrial laser scanning [7840-13]

D. Hoffmeister, A. Bolten, C. Curdt, G. Waldhoff, G. Bareth, Univ. of Cologne (Germany)

7840 OF Spatial relation query based on geographic ontology [7840-14]

C. Du, Capital Normal Univ. (China) and Institute of Geographic Science and Natural Resources Research, CAS (China); J. Xu, Institute of Geographic Science and Natural Resources Research, CAS (China); J. Zhang, Capital Normal Univ. (China); W. Si, Chang'an Univ. (China); B. Liu, D. Zhang, Capital Normal Univ. (China)

7840 OG A new climatic index for mapping world vegetation distribution [7840-15]

Y. Sun, Tianjin Normal Univ. (China) and Institute of Atmospheric Physics, CAS (China); P. Guo, Tianjin Normal Univ. (China); X. Yan, G. Jia, Institute of Atmospheric Physics, CAS (China)

$7840 \mathrm{OH}$ The review and prospect of GIS platform technologies [7840-16]

Z. Yang, SuperMap Software Co., Ltd. (China); G. Song, E. Zhong, SuperMap Software Co., Ltd. (China) and Institute of Geographic Sciences and Natural Resources Research, CAS (China)

7840 ol Situation-aware GeoVisualization considering applied logic and extensibility: a new architecture and mechanism for intelligent GeoWeb [7840-17]

X. He, Univ. College London (United Kingdom); C. Gold, Univ. of Glamorgan

(United Kingdom) 
$7840 \mathrm{OJ} \quad$ Estimating the presence of people from aggregate cell phone network activity [7840-18] A. Vaccari, SENSEable City Lab., Massachusetts Institute of Technology (United States); F. L. S. Pasini, Columbia Univ. (United States)

7840 OK Collaborative tool for collecting reference data on the density of constructed surfaces worldwide [7840-19]

C. D. Elvidge, NOAA National Geophysical Data Ctr. (United States); B. T. Tuttle, Univ. of Colorado, Boulder (United States) and Univ. of Denver (United States); P. C. Sutton, Univ. of Denver (United States)

$7840 \mathrm{OL} \quad$ Using graphics processing units as stream-processors for real-time simulation of high-resolution synthetic aperture radar images [7840-20]

T. Balz, Wuhan Univ. (China)

$78400 \mathrm{M}$ The capability and development of global change sensitive factor detection with Earth observation techniques: a case study of detecting snow cover [7840-21]

L. Zhao, Ctr. for Earth Observation and Digital Earth, CAS (China) and Graduate Univ. of the Chinese Academy of Science (China); Z. Li, Ctr. for Earth Observation and Digital Earth, CAS (China)

WEB-BASED SERVICES, SYSTEM DESIGN, AND ALGORITHMS FOR DIGITAL EARTH

7840 ON Integrated assessment systems of degraded marsh wetlands using RS coupling with GIS [7840-22]

D. Zhou, Capital Normal Univ. (China) and Northeast Institute of Geography and Agricultural Ecology, CAS (China) and Jilin Univ. (China); X. Li, Capital Normal Univ. (China); H. Zhang, Northeast Institute of Geography and Agricultural Ecology, CAS (China); S. Li, Capital Normal Univ. (China)

784000 A GIServices-based transportation information resources integration platform [7840-23] J. Hu, Q. Ma, Shenzhen Institute of Advanced Technology, CAS (China); Y. Wang, J. Zhou, Shanghai Highway Administrator Office (China)

7840 OP Submarine pipelines routing planning based on GIS and dynamic programming [7840-24] Y. Gao, North China Sea Branch of the State Oceanic Administration (China); H. Wang, QingDao Univ. of Science \& Technology (China); B. Wang, L. Yang, Z. Shi, North China Sea Branch of the State Oceanic Administration (China)

$7840 \mathrm{OQ}$ Using digital earth to create online scientific reality tourist guides to tourist attractions in Taiwan, China [7840-25]

Y.-C. Ding, Chinese Culture Univ. (China)

7840 OR Research on building a geographic information services portal oriented web services [7840-26]

Q. Li, H. Li, R. Liang, Information Engineering Univ. (China)

7840 OS WebMapping at school [7840-27]

N. de Lange, Univ. Osnabrück (Germany)

7840 OT Forest fire autonomous decision system based on fuzzy logic [7840-28]

Z. Lei, J. Lu, Tsinghua Univ. (China) 
7840 OU Research of a synchronized cooperative GIS system based on message [7840-29] Y. Sun, P. Du, China Univ. of Mining \& Technology (China); L. Zhou, Nanjing Normal Univ. (China)

7840 OV A proposed architecture for emergency response systems based on Digital Earth [7840-30] D. Li, C. Cheng, Peking Univ. (China)

$7840 \mathrm{OW}$ The design and implementation of a global satellite image organization and web-based publication system [7840-31]

J. Jiang, R. Cao, L. Wu, National Univ. of Defense Technology (China)

7840 OX Synthetic aperture radar image simulation system [7840-32]

Q. Xing, Ctr. for Earth Observation and Digital Earth, CAS (China) and Graduate Univ. of the Chinese Academy of Sciences (China); Z. Li, Q. Chen, Ctr. for Earth Observation and Digital Earth, CAS (China)

7840 OY The design and implementation of the HY-1B Product Archive System [7840-33] S. Liu, Ctr. for Earth Observation and Digital Earth, CAS (China); W. Liu, Ctr. for Earth Observation and Digital Earth, CAS (China) and Graduate Univ. of Chinese Academy of Sciences (China); H. Peng, National Satellite Ocean Application Service (China)

$7840 \mathrm{OZ}$ Meteorological disaster management and assessment system design and implementation [7840-34]

W. Tang, B. Luo, H. Wu, China Meteorological Administration (China)

784010 Development of a tool using satellite products for volcanic eruption monitoring [7840-35] C. Spinetti, L. Colini, M. F. Buongiorno, F. Doumaz, V. Lombardo, M. Musacchio, M. I. P. Apa, Istituto Nazionale di Geofisica e Vulcanologia (Italy)

784011 An algorithm of real-time vehicle detection with low altitude aerial video [7840-36] W. Wang, L. Tang, Q. Li, Wuhan Univ. (China)

784012 An algorithm for extracting terrain structure lines based on contour data [7840-37] H. Liu, H. Jin, B. Miao, Henan Polytechnic Univ. (China) and Dalian Univ. (China)

784013 Simplify the RFM based on the anti-ill-posed algorithms [7840-38]

L. Chen, Ctr. for Earth Observation and Digital Earth, CAS (China) and Graduate Univ. of the Chinese Academy of Sciences (China); W. Jiao, Ctr. for Earth Observation and Digital Earth, CAS (China)

784014 The application of Quadtree algorithm to information integration for geological disposal of high-level radioactive waste [7840-39]

M. Gao, S. Huang, X. Zhong, Beijing Research Institute of Uranium Geology (China)

784015 Progressive simplification and transmission of building polygons based on triangle meshes [7840-40]

H. Li, Y. Wang, Institute of Geographical Sciences and Natural Resources Research, CAS (China); Q. Guo, Wuhan Univ. (China); J. Han, Institute of Geographical Sciences and Natural Resources Research, CAS (China) 
784016 Prototype application for web 3D routing in building [7840-41]

M. Ehlers, I. Hijazi, Univ. Osnabrück (Germany)

784017 Simulation of 3D tidal flat topography based on fractional Brownian motion [7840-42] X. Li, W. Wu, Y. Zhou, J. Zhang, East China Normal Univ. (China)

784018 Three-dimensional visualization analysis for marine field data based on 3D-GIS [7840-43] X. Gao, T. Zhang, Institute of Geographical Sciences and Natural Resources Research, CAS (China)

784019 The virtual reality 3D city of Ningbo [7840-44]

W. Chen, D. Wu, Ningbo Design Research Institute of Mapping and Surveying (China)

7840 1A Research into the method for construction of interactive virtual reality scenes based on Ajax technology: a case study [7840-45]

J. Deng, X. Zheng, China Univ. of Geosciences (China)

7840 1B Realistic terrain visualization based on 3D virtual world technology [7840-46]

F. Huang, H. Lin, Chinese Univ. of Hong Kong (China); B. Chen, C. Xiao, Peking Univ. (China)

7840 1C Application of laser scanning technology to 3D urban landscape modeling [7840-47] J. Wang, F. Jin, X. Zhao, Y. Li, Shandong Univ. of Science and Technology (China)

7840 1D Visualization of the concentration distribution of Asian dust in the Google Earth [7840-48] T. Kusaka, T. Kono, W. Okuda, Kanazawa Institute of Technology (Japan); Y. Nakano, Kosaido Co., Ltd, (Japan)

7840 IE IDP camp evolvement analysis in Darfur using VHSR optical satellite image time series and scientific visualization on virtual globes [7840-49]

D. Tiede, S. Lang, Univ. Salzburg (Austria)

$7840 \mathrm{IF} \quad$ Modeling a 3D world: challenges, progress, and opportunities [7840-50]

T. Belayneh, Environmental Systems Research Institute (United States)

$78401 \mathrm{G}$ Simulation of microwave brightness temperature between 1-100GHz in Tibet using a coupled land-canopy-atmosphere model [7840-51]

X. Fu, Beijing Institute of Petrochemical Technology (China) and Institute of Remote Sensing Application, CAS (China) and Graduate Univ. of the Chinese Academy of Sciences (China); Y. Guo, Graduate Univ. of the Chinese Academy of Sciences (China)

\section{INFORMATION EXTRACTION AND DATA MINING METHODS}

$7840 \mathrm{1H}$ Stratified and automatic information extraction from high-resolution satellite imagery based on an object-oriented method [7840-52]

T. Jiang, Shandong Univ. of Science and Technology (China) and State Bureau of Surveying and Mapping (China); L. Fang, W. Ding, Shandong Univ. of Science and Technology

(China) 
$784011 \quad$ A new method of extracting shape features from IKONOS imagery based on Fourier Descriptor: an application to object-oriented classification [7840-53]

W. Wan, X. Feng, P. Xiao, L. Zhao, Nanjing Univ. (China)

7840 iJ A novel method of color image denoising based on the grey difference information principle [7840-54]

Z. Lai, State Oceanic Administration (China)

$78401 \mathrm{~K}$ Research on the management and quality detection of massive multibeam sounding data [7840-55]

L. Hua, Huazhong Agricultural Univ. (China); H. Sui, Wuhan Univ. (China) and South China Univ. of Technology (China); Y. Nong, J. Du, Wuhan Univ. (China)

$7840 \mathrm{IL} \quad$ Urban major road extraction from IKONOS imagery based on modified texture progressing analysis technique [7840-56]

X. WU, H. XU, P. Wu, Fuzhou Univ. (China)

$78401 \mathrm{M}$ Terrain description in Distributed Spatial Data Markup Language and visualization implemention [7840-57]

L. Huang, X. Zhu, J. Chen, Wuhan Univ. (China)

7840 iN Implementing a global DEM database on the sphere based on spherical wavelets [7840-58] D. Zhao, X. Zhao, S. Shan, L. Yao, China Univ. of Mining \& Technology (China)

784010 Grid transformation method of population data combining geographic factors and simulated township boundary adjustment [7840-59]

J. Han, H. Li, Institute of Geographical Sciences and Natural Resources Research, CAS

(China); L. Ma, Supermap Software Co., Ltd. (China)

7840 iP Characteristics of full-waveform lidar data from typical objects and its potential in point cloud classification [7840-60]

G. Xu, Institute of Forest Resource and Information Technology, CAF (China) and Nanjing Forestry Univ. (China); Y. Pang, Institute of Forest Resource and Information Technology, CAF (China); L. Yuan, Jiangsu Province Jinwei Remote Sensing Data Engineering Co., Ltd.

(China); M. Li, Nanjing Forestry Univ. (China); T. Fu, Institute of Forest Resource and Information Technology, CAF (China)

$78401 Q \quad$ On the comparison of spatial interpolation methods of marine temperature and salinity based on Arcgis software: a case study of Tianjin coastal waters in the Bohai Bay [7840-61] W. Li, W. Liu, Y. Zhang, W. Yin, Y. Liu, Tianjin Univ. of Science and Technology (China)

7840 IR An automatic precision registration method based on SIFT and Harris feature for multi-source remote sensing images [7840-62]

Y. Ye, L. Liu, L. Lin, Q. Fan, Wuhan Univ. (China)

7840 is Optimization of monitoring points on atmospheric pollution based on RS, GIS, and in-situ data [7840-63]

H. He, Guizhou Univ. for Nationalities (China); H. Fan, Wuhan Univ. (China) 
7840 iT Features extraction from multi-date ASTER imagery using a hybrid classification method for land cover transformations [7840-64]

E. Tarantino, Polytechnic Univ. of Bari (Italy)

$78401 \mathrm{U}$ Geometric evaluation of SPOT5 image using rigorous sensor model and simple polynomial direct location model [7840-65]

D. Yan, Ctr. for Earth Observation and Digital Earth, CAS (China); F. Wang, T. Kou, Ctr. for Earth Observation and Digital Earth, CAS (China) and Graduate Univ. of the Chinese Academy of Sciences (China); S. Chen, National Disaster Reduction Ctr. of China (China)

$7840 \mathrm{IV} \quad$ Methods on defining the urban fringe area of Beijing [7840-66]

$X$. Wang, X. Li, Z. Feng, Y. Fang, Beijing Forestry Univ. (China)

7840 IW Incremental updating geospatial data by granular computing [7840-67]

C. Shen, Heilongjiang Land Resource Surveying and Planning Institute (China) and Wuhan Univ. (China); Y. Song, Wuhan Univ. (China)

7840 1X A new method of road extraction from high-resolution remote sensing imagery [7840-68] C. Ni, Z. Guan, Q. Ye, Tongji Univ. (China)

7840 IY A remotely sensed image fusion method based on non-subsampled contourlet transform and human visual system [7840-69]

B. Cheng, Ctr. for Earth Observation and Digital Earth, CAS (China); Y. Zhan, China Land Surveying and Planning Institute (China); J. Zhang, Ctr. for Earth Observation and Digital Earth, CAS (China) and Graduate Univ. of the Chinese Academy of Sciences (China)

$78401 \mathrm{Z}$ The design and realization of a socio-economic statistical spatio-temporal database [7840-70]

C. Yang, X. Li, Q. Liu, H. Zhao, J. Zhang, H. Zhang, Capital Normal Univ. (China)

784020 SWOT analysis on National Common Geospatial Information Service Platform of China [7840-71]

X. Zheng, National Geomatics Ctr. of China (China); B. He, Wuhan Univ. (China)

784021 An experimental comparison of ETM+ image geometric correction methods in the mountainous areas of Yunnan Province, China [7840-72]

J. Wang, Yunnan Normal Univ. (China); X. Wu, Yunnan Normal Univ. (China) and Cold and Arid Regions Environmental and Engineering Research Institute, CAS (China)

784022 Quantitative retrieval of aerosol optical thickness from FY-2 VISSR data [7840-73]

L. Bai, Institute of Remote Sensing Applications, CAS (China) and Graduate Univ. of the Chinese Academy of Sciences (China) and Ctr. for Earth Observation and Digital Earth, CAS (China); Y. Xue, Institute of Remote Sensing Applications, CAS (China) and London Metropolitan Univ. (United Kingdom); C. Cao, Institute of Remote Sensing Applications, CAS (China); J. Feng, Institute of Agricultural Resources and Regional Planning, CAAS (China);

H. Zhang, Institute of Remote Sensing Applications, CAS (China); J. Guang, Y. Wang, Y. Li, L. Mei, J. Ai, Institute of Remote Sensing Applications, CAS (China) and Graduate Univ. of the Chinese Academy of Sciences (China) 
784023 New satellite-based maps of the growing season north of $50^{\circ} \mathrm{N}$ [7840-74]

S. Rune Karlsen, K. Arild Høgda, Northern Research Institute Tromsø (Norway); A. Tolvanen, Finnish Forest Research Institute (Finland); B. Johansen, Northern Research Institute Troms $\varnothing$ (Norway); A. Elvebakk, Univ. of Tromsø (Norway)

784024 Algal bloom mapping using MODIS [7840-75]

M. Valappil Nitin, GIS Consultant (India)

784025 Study of the model of calibrating differences of brightness temperature from geostationary satellite generated by time zone differences [7840-76]

W. Li, China Earthquake Administration (China) and Henan Univ. of Technology (China);

X. Shan, C. QU, China Earthquake Administration (China)

Author Index 


\section{Organizing Structure of the 6th International Symposium on Digital Earth}

\section{Organizers}

International Society for Digital Earth (ISDE)

Chinese Academy of Sciences (CAS)

\section{Co-Organizers}

Ministry of Science and Technology, P.R. China

Ministry of Land and Resources, P.R. China

Ministry of Environmental Protection, P.R. China

Ministry of Housing and Urban-Rural Development, P.R. China

Beijing Municipal Government, P.R. China

China Association for Science and Technology

Chinese Academy of Engineering

China Earthquake Administration

China Meteorological Administration

National Natural Science Foundation of China

State Oceanic Administration, P.R. China

State Bureau of Surveying and Mapping, P.R. China

United Nations Educational, Scientific and Cultural Organization (UNESCO)

Joint Research Center of the European Commission

Canada Center for Remote Sensing

\section{Hosts}

Chinese National Committee, ISDE

Center for Earth Observation and Digital Earth, CAS

\section{Co-Hosts}

National Remote Sensing Center of China

National Disaster Reduction Center of China

National Geomatics Center of China

Institute of Geographic Sciences and Natural Resources

Research, CAS

Institute of Remote Sensing Applications, CAS

China Aero Geophysical Survey \& Remote Sensing Center for Land and Resources

China Center for Resource Satellite Data and Applications

National Satellite Meteorological Center

National Satellite Ocean Application Service

Institute of Digital China, Peking University

Beijing Municipal Commission of Economy and Information Technology

LIESMARS, Wuhan University 
Downloaded From: https://www.spiedigitallibrary.org/conference-proceedings-of-spie on 26 Apr 2023

Terms of Use: https://www.spiedigitallibrary.org/terms-of-use 


\title{
Conference Committees
}

\author{
ISDE Executive Committee
}

President

Prof. LU Yongxiang, Chinese Academy of Sciences, CAS (China)

Vice Presidents

Dr. Marc D'lorio, Geological Survey of Canada (Canada)

Prof. Milan Konecny, Masaryk University (Czech Republic)

Secretary General

Prof. GUO Huadong, Center for Earth Observation and Digital Earth, CAS (China)

Members

Adigun Ade Abiodun, United Nations Committee on the Peaceful Uses of Outer Space

Alessandro Annoni, Institute for Environment and Sustainability, JRC, EU

Armin Gruen, Institute of Geodesy and Photogrammetry, ETH (Switzerland)

CHEN Yuntai, Institute of Geophysics, State Seismological Bureau (China)

David Rhind, City University (United Kingdom)

Fred Campbell, Canada FC Consulting (Canada)

HE Changchui, Food and Agriculture Organization, United Nations

Gabor Remetey-Fülöpp, Hungarian Association for Geo-information (Hungary)

Hiromichi Fukui, Keio University (Japan)

John L. van Genderen, ITC (Netherlands)

Jean Sequeira, University of Marseilles (France)

John Townshend, Maryland University (United States)

Mario Hernandez, UNESCO Remote Sensing Unit

Manfred Ehlers, University Osnabrück (Germany)

Mike Goodchild, University of California (United States)

Peter Woodgate, Cooperative Research Center for Spatial Information,

(Australia)

Richard Simpson, University of Auckland (New Zealand)

Tim W. Foresman, International Center for Remote Sensing Education

(United States)

C. Vicent Tao, Microsoft Corporation (United States)

Werner Alpers, University of Hamburg (Germany)

XU Guanhua, Ministry of Science and Technology (China) 
International Steering Committee

Chair

LU Yongxiang, Chinese Academy of Sciences

Members

Adigun Ade Abiodun, UN Committee on the Peaceful Uses of Outer Space

Armin Gruen, Swiss Federal Institute of Technology (Switzerland)

CAO Jianlin, Ministry of Science and Technology (China)

CHEN Yiyu, National Natural Science Foundation of China (China)

D. R. Fraser Taylor, International Steering Committee for Global Mapping

David Rhind, City University (United Kingdom)

Gilberto Camara, National Institute for Space Research (Brazil)

HE Changchui, FAO, UN

Ian Dowman, ISPRS

JIANG Mianheng, Chinese Academy of Sciences (China)

John Townshend, Maryland University (United States)

José Achache, GEO Secretariat

Marc D'lorio, Canada Geological Survey (Canada)

Mario Hernandez, Remote Sensing Unit, UNESCO

Martti Hallikainen, Helsinki University of Technology (Finland)

Milan Konecny, Masaryk University (Czech Republic)

Myra Bambacus, NASA Geosciences Interoperability Office (United States)

QIN Dahe, Chinese Academy of Sciences (China)

Shunji Murai, Asian Association on Remote Sensing

Stuart Salter, Canada Centre for Remote Sensing (Canada)

SUN Honglie, Chinese Academy of Sciences (China)

SUN Laiyan, China National Space Administration

Vladimir S. Tikunov, Moscow State University (Russian Federation)

WANG Qinmin, Fuzhou University (China)

William Cartwright, International Cartographic Association

International Scientific Committee

Co-Chairs

XU Guanhua, Ministry of Science and Technology (China)

Michael F. Goodchild, University of California (United States)

\section{Members}

Alessandro Annoni, Joint Research Center, European Commission

Alfred Stein, ITC (Netherlands)

Anthony G.O. Yeh, Hong Kong University (Hong Kong, China)

CHAO Jiping, National Marine Environment Forecast Center (China)

CHEN Junyong, State Bureau of Surveying and Mapping (China)

CHEN Yong, China Earthquake Administration (China)

CHEN Yuntai, Institute of Geophysics, China Earthquake Administration (China)

David J. Coleman, University of New Brunswick (Canada) 
DING Zhongli, Chinese Academy of Sciences (China)

Fred Campbell, Canada Centre for Remote Sensing (Canada)

FU Congbin, Institute of Atmospheric Physics, CAS (China)

Gabor Remetey-Fülöpp, Hungarian Association for Geo-information (Hungary)

GAO Jun, Information Engineering University (China)

Hiromichi Fukui, Keio University (Japan)

Jean Sequeira, University of Marseilles (France)

John L. van Genderen, ITC (Netherlands)

uI Deren, Wuhan University (China)

LI Xiaowen, Beijing Normal University (China)

LIU Changming, Institute of Geographic Science and Natural Resources

Research, CAS (China)

Luigi Fusco, European Space Agency

MA Zongjin, Institute of Geology, China Earthquake Administration (China)

Manfred Ehlers, University of Osnabrueck (Germany)

OUYANG Ziyuan, National Astronomical Observatories, CAS (China)

Paul Uhlir, National Academy of the United States (United States)

Peter Woodgate, Cooperative Research Centre for Spatial Information,

(Australia)

Richard Simpson, University of Auckland (New Zealand)

SU Jilan, The Second Institute of Oceanography, SOA (China)

SUN Shu, Institute of Geology and Geophysics, CAS (China)

Tim W. Foresman, International Center for Remote Sensing Education

(United States)

TONG Qingxi, Institute of Remote Sensing Applications, CAS (China)

Vincent Tao, Microsoft Corporation (Unites States)

WANG Jiyang, Institute of Geology and Geophysics, CAS (China)

ZHAO Pengda, China University of Geosciences (China)

ZHOU Xiuji, Chinese Academy of Meteorological Sciences (China)

Organizing Committee

Chair

GUO Huadong, Center for Earth Observation and Digital Earth, CAS (China)

Vice Chairs

CAO Jinghua, Chinese Academy of Sciences (China)

CHAl Yucheng, National Natural Science Foundation of China (China)

CHEN Ligong, Beijing Municipal Government (China)

CHENG Jiayi, Chinese Academy of Engineering (China)

HAN Aixing, Ministry of Housing and Urban-Rural Development (China)

LI Mingmei, China Meteorological Administration (China)

LI Zhijian, Ministry of Land and Resources (China)

LIAO Xiaohan, Ministry of Science and Technology (China)

LIANG Yingnan, China Association for Science and Technology (China)

MENG Shuguang, Ministry of Science and Technology (China)

SHI Suixiang, State Oceanic Administration (China)

XU Yanying, State Bureau of Surveying and Mapping (China) 
ZHAO Ming, China Earthquake Administration (China)

ZHAO Yingmin, Ministry of Environmental Protection (China)

\section{Members}

CHEN Jun, National Geomatics Center of China (China)

CHEN Xiuwan, Institute of Digital China, Peking University (China)

CHEN Xuanqing, National Development and Reform Commission (China)

DONG Baoqing, Ministry of Industry and Information Technology (China)

FAN Yida, National Disaster Reduction Center of China (China)

GAO Wei, East China Normal University (China)

GU Xingfa, Institute of Remote Sensing Applications, CAS (China)

GUO Jianning, China Center for Resource Satellite Data and Applications (China)

JIANG Xingwei, National Satellite Ocean Application Service (China)

JU Jianhua, Ministry of Land and Resources (China)

LI Xiaobo, Ministry of Land and Resources (China)

LI Zengyuan, Chinese Academy of Forestry (China)

LI Zhizhong, China Aero-Geophysical Survey \& RS Center for Land and Resources (China)

LIN Hui, Chinese University of Hong Kong

LIU Dingsheng, Center for Earth Observation and Digital Earth, CAS (China)

LIU Yongwei, Center for Earth Observation and Digital Earth, CAS (China)

MA Jianwen, Center for Earth Observation and Digital Earth, CAS (China)

MIN Yiren, State Bureau of Surveying and Mapping (China)

SHAO Yun, Institute of Remote Sensing Applications, CAS (China)

SHI Peiliang, China Meteorological Administration (China)

SONG Changqing, National Natural Science Foundation of China (China)

SU Xiaojun, China Association for Science and Technology (China)

TIAN Jing, Bureau of High-Tech Research and Development, CAS (China)

WANG Qiao, China National Environmental Monitoring Center (China)

WANG Zhenyu, Bureau of International Cooperation, CAS (China)

WU Zhongliang, China Earthquake Administration (China)

YANG Chongjun, Institute of Remote Sensing Applications, CAS (China)

YANG Jun, National Satellite Meteorological Center (China)

ZHANG Bing, Center for Earth Observation and Digital Earth, CAS (China)

ZHANG Guocheng, National Remote Sensing Center of China (China)

ZHOU Chenghu, Institute of Geographic Sciences and Natural Resources Research, CAS (China)

\section{Secretariat}

Secretary-General

\section{ZHANG Bing}

Deputy Secretaries-General

LIU Yongwei, WANG Changlin, WANG Zhengyu, SHEN Yimin, MA Jianwen

ZHU Boqin, WANG Xinyuan, LIU Jie, HUANG Mingrui 


\section{Conference Chairs}

GUO Huadong, Center for Earth Observation and Digital Earth, CAS (China)

WANG Changlin, International Society for Digital Earth

GAO Wei, Colorado State University (United States)

Session Chairs

10 September 2009

Plenary Sessions

Michael Goodchild, LI Deren

CHEN Yuntai, Paul Uhlir

\section{Parallel Sessions}

Digital Earth Frameworks, Models, and Data Warehouse

Gabor Remetey-Fulopp, SHAO Yun

Web Based Service for Digital Earth

Giuseppe Vilardo, YANG Chaowei

Digital Earth Geobrowser, Virtual Global and Simulation I

Tim Foresman, GONG Jianhua

Digital Earth Geobrowser, Virtual Global and Simulation II

David Wortley, Ya Chun Yu

Digital Earth and Global Environment I

Anthony Lewis, ZHANG Ying

Digital Earth and Global Environment II

Wayne Walsh, YANG Liming

Spatial Data Infrastructure for Digital Earth

Alessandro Annoni, HE Guojin

Virtual Environment for Digital Earth

LIN Hui, Ifan D H Shepherd

Earth Observation for Digital Earth

ZHANG Bing, Claudia Kuenzer

Digital Ocean

TANG Danling, Homayoun Khoashravan

Special Session for International Journal of Digital Earth

John van Genderen, Christina Low

Planet Action Contribution to Digital Earth

Louis-Francois Guerre, LIU Jianbo

Data Service Infrastructure for Global Change Research I

LIU Chuang, Nordin Hasan

Data Service Infrastructure for Global Change Research II

LIU Dingsheng, Linda Anne Stevenson 
11 September 2009

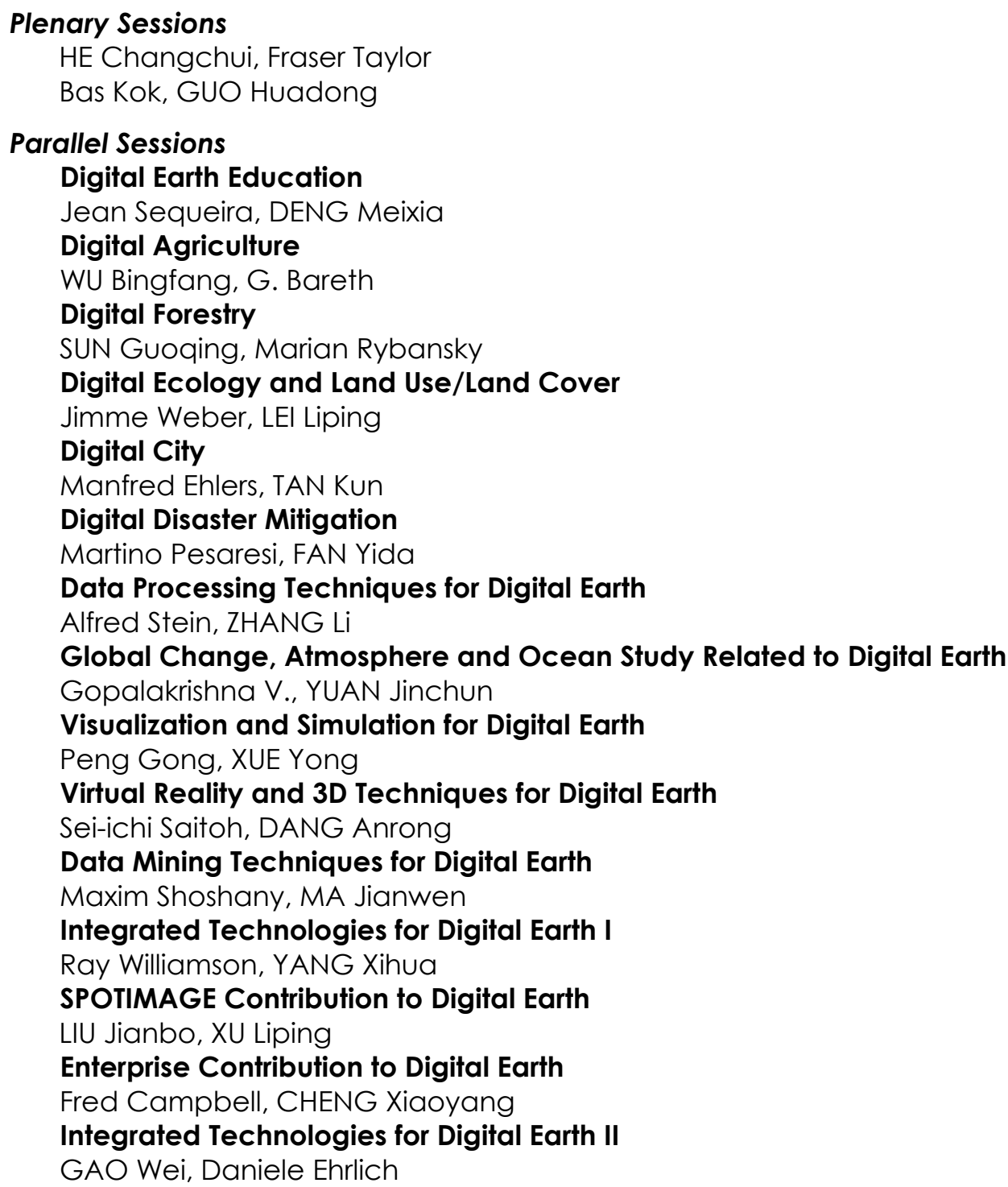

12 September 2009

Plenary Sessions

Robert Chen, Peter Woodgate

Mario Hernandez, Armin Gruen

Parallel Sessions

Digital Heritage

Mario Hernandez, WANG Changlin

Digital Ecology and Environment

SHI Jiancheng, William Sprigg

Airborne Remote Sensing 
Randal T. Albertson, LI Jingwei

Integrated Technologies for Digital Earth III

Kyle Hence, ZHANG Yuanzhi

Network System and Data Processing Techniques for Digital Earth

Jan Kolar, Hiromichi Fukui

Geospatial Data Solution for Digital Earth

Michael Abrams, LI Zhen 
Downloaded From: https://www.spiedigitallibrary.org/conference-proceedings-of-spie on 26 Apr 2023

Terms of Use: https://www.spiedigitallibrary.org/terms-of-use 


\section{Foreword}

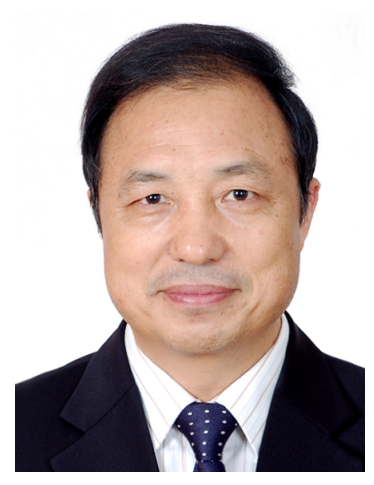

The Digital Earth Symposia have been held every two years, since the First International Symposium on Digital Earth was convened in Beijing in 1999. The symposia were held next in Canada, the Czech Republic, Japan and the United States from 2001 to 2007. The Sixth International Symposium on Digital Earth (the Sixth ISDE) was held in Beijing, 9-12 September, 2009. The theme of this symposium was Digital Earth in Action, and topics covered a range of technological advances and emerging applications, linking Digital Earth with many other related sciences and technologies.

It is exciting to see that, over the past ten years, the Digital Earth concept has become more and more widespread, as the Digital Earth technological applications have touched wider and wider aspects of society. People will learn more about this powerful tool, to fully apply it to their lives to promote information sharing, and solve various natural problems. These include topics such as natural resource shortages, environmental degradation, energy security and Global Change. On these points, the Sixth ISDE, as an international academic platform, played an important role in consolidating improvements and the further implementation of Digital Earth from concept into action.

These Proceedings consist of two volumes, with 147 research papers in total. All the papers included were selected through international Peer-Review by a Scientific Committee. Volume 7840 is comprised of sessions on the Digital Earth framework, models and spatial data infrastructure; web based services, system design and algorithms for digital earth; 3D Technology, virtual reality and visualization, information extraction, and data mining methods. Volume 7841 covers sessions on image processing and analysis, synthetic aperture radar data processing and analysis, digital earth applications in ecology, agriculture, and resources; disaster and hydrology, and digital earth applications for urban studies and heritage. Volume 7840 focuses more on the development of digital earth theory and technology, while Volume 7841 stresses applications of digital earth in each field, and includes some case studies. Through academic exchanges and discussions on current and developing trends in Digital Earth science and technology, it is becoming much easier for people to understand the Digital Earth concept, which integrates and combines Digital Earth technology with other fundamental research, technical developments, resources, environmental management, and disaster monitoring. 
At the opening of these Proceedings, a speech entitled "Jointly Building the Digital Earth and Bringing Benefits to Mankind" by Her Excellency Madam LIU Yandong, state councilor of the State Council, China was given, and another entitled "Creating a Bright Future for Digital Earth" by Prof. LU Yongxiang, President of the International Society for Digital Earth, and President of the Chinese Academy of Sciences, was given, and these are included. And, two Declarations on Digital Earth, milestones in the history of development of Digital Earth science and technology, are also presented. At the First International Symposium on Digital Earth, the 1999 Beijing Declaration on Digital Earth was promulgated. Ten years later, at the Sixth ISDE, the 2009 Beijing Declaration on Digital Earth was approved and adopted by all attendees. It is clear through the contrasts in the two declarations that, during the past ten years, considerable progress has been made on Digital Earth. People's understanding of Digital Earth has changed from "vague" to "clear". This is particularly true in that Digital Earth is not only being applied in addressing social and economic problems, but is playing a more active role in much wider fields, for example, Global Change. This is in one of the objectives of the International Society for Digital Earth, one of the organizers of the Sixth ISDE, and which promotes international cooperation through Digital Earth to reach the ultimate goal of global sustainable development.

I would like to take this opportunity of the publication of these Proceedings to express my gratitude to the International Scientific Committee members of the Sixth ISDE for their contributions to the convening of this symposium, and also to the Organizing Committee members for their tireless efforts in preparing this fantastic symposium. I am grateful for the paper authors for the time and ideas they have contributed to the Symposium. Editorial Board members and reviewers, especially Profs. John van Genderen, Anthony J. Lewis and Fred Campbell are thanked for their work and devotion to the publication of these Proceedings. Special thanks are also expressed to Prof. GAO Wei, Organizing Committee Member from Colorado State University, for his direction and help with the final publication of these Proceedings. I also would like to extend my sincere thanks to SPIE for publishing the Proceedings. My thanks also go to Prof. LIU Yongwei, Prof. WANG Changlin, Ms. LIU Jie, Ms. LIU Zhen and Mr. JIANG Hao for their professional suggestions and editorial assistance.

Finally, I am honored to present these Proceedings and hope everyone enjoys them.

GUO Huadong

Chairman

Organizing Committee of the Sixth ISDE

Chairman

Chinese National Committee for ISDE

Director General

Center for Earth Observation and Digital Earth

Chinese Academy of Sciences 


\section{Opening Speech:}

\section{Jointly Building the Digital Earth and Bringing Benefits to Mankind}

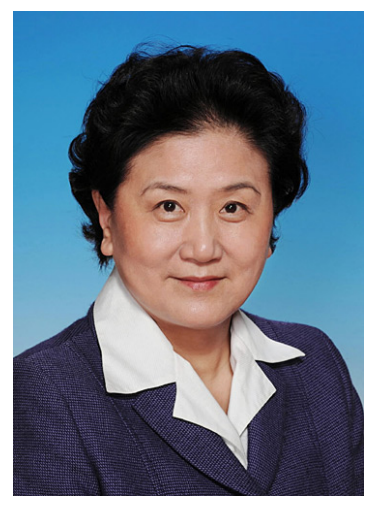

Her Excellency Madam LIU Yandong

State Councilor, State Council of China

Distinguished experts, delegates, ladies and gentlemen,

On this, the opening Ceremony of the 6th International Symposium on Digital Earth (ISDE6), on behalf of the Chinese government, I would like to express my congratulations on the opening of the Symposium and extend a warm welcome to experts, scholars and delegates from around the world! With the theme of "Digital Earth in Action", this Symposium will focus on the critical global issue of "building the Digital Earth and coping with Global Change". It is committed to promoting research, exchange and cooperation in Digital Earth theories and technologies, and their applications. It will have a profound and positive effect on strengthening our understanding of the role of Digital Earth in Global Change and promoting Digital Earth to better serve the survival and development of mankind.

Since the late 20th century, we have entered the age of information, and great changes have taken place in many areas, such as economic development, people's lives and governance, etc., due to rapid development and extensive application of information technology. Through the joint efforts of the governments, scientific communities, and enterprises of all countries, Digital Earth, developed using space science and technology, information science and technology, and geoscience, has made remarkable progress in various aspects of resource investigations, climate prediction, weather forecast, natural disaster monitoring, agricultural production estimates and regional planning, etc. It has become the best way to integrate, use, and share existing data and information, as well as a core data source for sustainable development, thus playing an increasingly important role in economic and social development. 
Presently, all countries are facing a number of major issues that need to be addressed through joint efforts. These include topics such as climate change, energy conservation, emissions reduction, eco-environmental protection, food security, disease control, heritage conservation, major natural disasters and global financial problems, etc. These have become established as the imperative requirements to build Digital Earth. I believe that building Digital Earth will help mankind to better understand and grasp natural systems, as well as economic and social systems. It will help us to develop a comprehensive understanding of the planet where we live, and accurately grasp major natural changes, production, life, etc. Digital Earth will also promote communication among people of all countries, and provide support to Governments to improve the accuracy, timeliness and coordination in decision-making.

At present, the Chinese Government has set a goal of building China into an innovation-oriented country and promoting IT applications in our National economic and social development is very important. We are integrating IT applications with industrialization, transforming development patterns, and taking a path of comprehensive, coordinated and sustainable development.

In response to the global financial crisis, the Chinese Government developed a plan to expand domestic demand and boost economic growth. This plan considers promotion of information applications as an important element, and has sharply increased the IT research and development budget and construction of information infrastructure facilities. The global financial crisis slowed China's revenue growth, but our investment in science and technology has still grown by $25 \%$ this year, and scientific and technological input in information fields accounts for a high percentage of this amount. History has shown that a serious economic and financial crisis will provide new opportunities for technical breakthroughs, emerging industrial development and industrial structure upgrading.

I am convinced that Digital Earth will provide essential support for global cooperation for sustainable development, a new growth sector for economic and social development, and a new tool for the progress of human civilization. Despite all the difficulties and challenges on the road ahead, our confidence and efforts to build the Digital Earth will never wane, and Digital Earth development in all countries, including China, will surely propel it to reach new levels!

Ladies and Gentlemen,

Cooperation for mutual benefit and simultaneous development has become a common expectation of people everywhere. Convening the ISDE6 will promote sharing and use of global information resources, and speed up development of Digital Earth. I am firmly convinced that building Digital Earth, narrowing the digital divide, 
and strengthening international cooperation will enable people around the world to reach the high-level economic and social development, progress, and better lives!

Finally, I wish the Symposium every success!

Thank you!

(Note: Translated according to Chinese speech manuscript, presented at the symposium by Prof. CAO Jianlin, Vice-Minister of Science and Technology of China) 
Downloaded From: https://www.spiedigitallibrary.org/conference-proceedings-of-spie on 26 Apr 2023

Terms of Use: https://www.spiedigitallibrary.org/terms-of-use 


\section{Opening Speech:}

\section{Creating a Bright Future for Digital Earth}

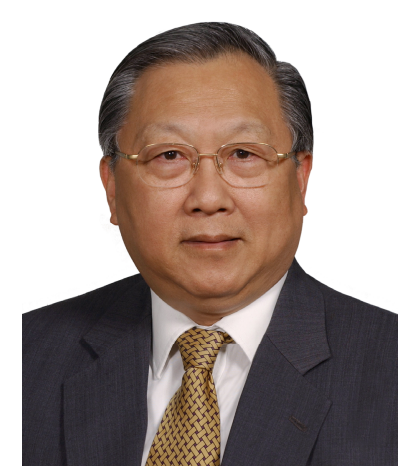

LU Yongxiang

Vice-Chairman of the Standing Committee, NPC,

President of the Chinese Academy of Sciences,

President of the International Society for Digital Earth

Honorable State Councilor Madam LIU Yandong,

Distinguished Guests,

Colleagues and Friends,

Ladies and Gentlemen,

Today we are very pleased to gather here to hold the 6th International Symposium on Digital Earth. Ten years ago (in 1999), it was in the same place that we held the first International Symposium on Digital Earth. What happened then is still vivid and fresh in my memory. Today, we are so happy to get together again in Beijing in this golden season to renew our friendship, to exchange our past and newest progress and development on Digital Earth and to look forward to a brighter future. First of all, on behalf of the International Society for Digital Earth and the Chinese Academy of Sciences, I would like to extend our warmest welcome to all participants in this symposium, particularly to our colleagues and friends who have traveled thousands of miles from all over the world.

The concept of Digital Earth came into existence about ten years ago. The successful holding of the first ISDE and the release of Beijing Declaration on Digital Earth in 1999 marked the official extension of Digital Earth worldwide. Science is borderless and people the world-over have come to a consensus. In spite of different cultures, scientific disciplines, industrial and technical backgrounds, scientists, decision-makers and entrepreneurs from all parts of the world have taken action faced with new scientific and technological developments. They have jointly promoted the development of Digital Earth by mutually beneficial exchange, cooperation and actions. 
It is such a pleasure and comfort for us to see the great achievements made worldwide in Digital Earth over the past decade. With the development of spatial information technology, network communication technology and earth system science, the shared Digital Earth platforms for both public and commercial use have come into existence. Some imaginative ideas have become, or are becoming, realities, with Digital Earth having entered households and changing the modes of production and lifestyles.

The past ten years have also witnessed academic progress in International Digital Earth. After the first ISDE held in China, the 2nd, 3rd, 4th and 5th symposium were held in Canada, the Czech Republic, Japan and the USA. International Digital Earth Summits were held respectively in New Zealand and Germany. In 2006, the International Society for Digital Earth was officially registered and established in Beijing. The society has become a home for all the academics in the field. In 2008, the Society published its official journal - International Journal of Digital Earth, in cooperation with Taylor \& Francis Publishing Group. So far, seven issues have been published.

Over the last ten years, the themes of the 7 International Digital Earth Symposia have ranged over topics such as "Toward Digital Earth", "Beyond the Information Infrastructure", "Information Resources for Global Sustainable Development", "Digital Earth as a Global Commons", "Digital Earth down to Earth", "Digital Earth and Sustainable Development" and "Digital Earth and Global Change" to the current one - "Digital Earth in Action", leaving a footprint showing the development of Digital Earth, from its initiation to its present level.

Today, ten years after its initiation, we are celebrating not only the development of Digital Earth, but also human confidence and actions to further promote its development, which has gone beyond the boundaries of space and time. Digital Earth has already become one of the most challenging and extensive scientifically driven fields. At a high, globally-strategic objective, Digital Earth integrates and optimizes Earth Observation technology, geographic information systems (GIS), global positioning system (GPS), network and communication technology, virtual reality technology and grid computing technology. As such, Digital Earth can make great contributions to socially-sustainable development.

Earth is the only planet on which mankind depends for our existence and survival. We are all responsible for its rational and reasonable exploitation and utilization, as well as its effective protection and environmental optimization. This is particularly the case in our facing the tremendous challenges brought about by Global Change in recent years. In the era of a global knowledge-based economy, supported by information and space technology today, Digital Earth is considered as the core of future information. With the challenges of global environmental protection and sustainable development, development of Digital Earth has a long way to go. We should enhance all-round global cooperation to promote data sharing, minimize the digital 
divide and boost a deeper and more extensive development of Digital Earth.

On Nov 29, 1999, in my report on the "Cooperation in the Development of Digital Earth and Sharing of Global Data Resources", at the first ISDE, I stated that: "We should set forth a unified scientific framework and a multi-level structure for Digital Earth. We need to explore the formulation of data sources and source-data standards and information exchange protocols based on independent development and global construction and sharing. We need to build a global network to ensure seamless global submissions and regular updates of earth observation data. We need to continuously improve user-friendly and visual interfaces. We must try to create transparent websites for visits and navigation, and we need to coordinate the formulation of international agreements and management standards for system efficiency and information security."

Today, I would like to further emphasize the need to pay particular heed to the applications of advanced Earth Observation technology, new generations of networking, search, browser and cloud computing technologies in the construction of Digital Earth to upgrade public services and reduce service costs. Let us unite our efforts to make Digital Earth available in every corner of the world, to make Digital Earth the information platform for decision-makers, and make Digital Earth the information home for all.

I wish you all closer cooperation and exchanges for a better and brighter Digital Earth tomorrow.

My best wishes for a successful Symposium.

Thank you. 
Downloaded From: https://www.spiedigitallibrary.org/conference-proceedings-of-spie on 26 Apr 2023

Terms of Use: https://www.spiedigitallibrary.org/terms-of-use 


\title{
Beijing Declaration on Digital Earth
}

\author{
Approved at the Closing Ceremony of the \\ $6^{\text {th }}$ International Symposium on Digital Earth \\ September 12, 2009
}

We scientists, engineers, educators, entrepreneurs, managers, administrators and representatives of civil societies from more than forty countries, international organizations and NGOs, once again, have assembled here, in the historic city of Beijing, to attend the Sixth International Symposium on Digital Earth, organized by the International Society for Digital Earth and the Chinese Academy of Sciences, with co-sponsorship of sixteen Chinese Government Departments, Institutions and international organizations, being held from September 9-12, 2009:

\section{Noting That}

Significant global-scale developments on Digital Earth science and technology have been made over the past ten years, and parallel advances in space information technology, communication network technology, high-performance computing, and Earth System Science have resulted in the rise of a Digital Earth data-sharing platform for public and commercial purposes, so that now Digital Earth is accessible by hundreds of millions, thus changing both the production and lifestyle of mankind;

\section{Recognizing}

The contributions to Digital Earth made by the host countries of the previous International Symposia on Digital Earth since November 1999, including China, Canada, the Czech Republic, Japan and the USA, and by the host countries of the previous Summit Conferences on Digital Earth, including New Zealand and Germany, for the success of the meetings as well as further promotion of Digital Earth;

Further, that the establishment of the International Society for Digital Earth and the accomplishments of its Executive Committee, the launch of the International Journal on Digital Earth, and its global contribution to 
cooperation and data exchange;

That the themes of the previous seven meetings: Moving towards Digital Earth, Beyond Information Infrastructure, Information Resources for Global Sustainability, Digital Earth as Global Commons, Bring Digital Earth down to Earth, Digital Earth and Sustainability, Digital Earth and Global Change, and Digital Earth in Action, have laid out a panoramic scenario for the future growth of Digital Earth;

That Digital Earth will be asked to bear increased responsibilities in the years to come, in the face of the problems of sustainable development;

\section{Further Recognizing}

That Digital Earth should play a strategic and sustainable role in addressing such challenges to human society as natural resource depletion, food and water insecurity, energy shortages, environmental degradation, natural disasters response, population explosion, and, in particular, global climate change;

That the purpose and mission of the World Information Summit of 2007, the Global Earth Observation System Conference of 2007, and the upcoming United Nations Climate Change Conference of 2009, and that Digital Earth is committed to continued close cooperation with other scientific disciplines;

\section{$\underline{\text { Realizing }}$}

That Digital Earth is an integral part of other advanced technologies including: earth observation, geo-information systems, global positioning systems, communication networks, sensor webs, electromagnetic identifiers, virtual reality, grid computation, etc. It is seen as a global strategic contributor to scientific and technological developments, and will be a catalyst in finding solutions to international scientific and societal issues;

\section{We Recommend}

a) That Digital Earth expand its role in accelerating information transfer from theoretical discussions to applications using the emerging spatial data infrastructures worldwide, in particular, in all fields related to global climate 
change, natural disaster prevention and response, new energy-source development, agricultural and food security, and urban planning and management;

b) Further, that every effort be undertaken to increase the capacity for information resource-sharing and the transformation of raw data to practical information and applications, and developed and developing countries accelerate their programs to assist less-developed countries to enable them to close the digital gap and enable information sharing;

c) Also, that in constructing the Digital Earth system, efforts must be made to take full advantage of next-generation technologies, including: earth observation, networking, database searching, navigation, and cloud computing to increase service to the public and decrease costs;

d) Further, that the International Society for Digital Earth periodically take the lead in coordinating global scientific research, consultations and popular science promotion to promote the development of Digital Earth;

e) Expanding cooperation and collaboration between the International Society for Digital Earth and the international community, in particular with inter-governmental organizations, and international non-governmental organizations;

f) Extending cooperation and integration with Government Departments, the international Scientific and Educational community, businesses and companies engaged in the establishment of Digital Earth;

\section{$\underline{\text { We Call for }}$}

Support from planners and decision-makers at all levels in developing plans, policies, regulations, standards and criteria related to Digital Earth, and appropriate investments in scientific research, technology development, education, and popular promotion of the benefits of Digital Earth. 
Downloaded From: https://www.spiedigitallibrary.org/conference-proceedings-of-spie on 26 Apr 2023

Terms of Use: https://www.spiedigitallibrary.org/terms-of-use 


\title{
Beijing Declaration on Digital Earth
}

\author{
Approved at the Closing Ceremony of the

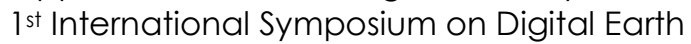

December 2, 1999

We, some 500 scientists, engineers, educators, managers and industrial entrepreneurs from 20 countries and regions assembled here in the historical city of Beijing, attending the first International Symposium on Digital Earth being organized by the Chinese Academy of Sciences with co-sponsorship of 19 organizations and institutions from November 29, 1999 to December 2, 1999, recognize that humankind, while entering into the new millennium, still faces great challenges such as rapid population growth, environmental degradation, and natural resource depletion which continue to threaten global sustainable development;

Noting that global development in the 20th century has been characterized by rapid advancements in science and technology which have made significant contributions to economic growth and social wellbeing and that the new century will be an era of information and space technologies supporting the global knowledge economy;

Realizing the decisions made at UNCED and Agenda 21, recommendations made by UNISPACE III and the Vienna Declaration on Space and Human Development, which address, among other things, the importance of the Integrated Global Observing Strategy, the Global Spatial Data Infrastructure, geographic information systems, global navigation and positioning systems, geo-spatial information infrastructures and modeling of dynamic processes;

Understanding that Digital Earth, addressing the social, economic, cultural, institutional, scientific, educational, and technical challenges, allows humankind to visualize the Earth, and all places within it, to access information about it and to understand and influence the social, economic and environmental issues that affect their lives in their neighborhoods, their nations and the planet Earth;

Recommend that Digital Earth be promoted by scientific, educational and 
technological communities, industry, governments, as well as regional and international organizations;

Recommend also that while implementing the Digital Earth, priority be given to solving problems in environmental protection, disaster management, natural resource conservation, and sustainable economic and social development as well as improving the quality of life of the humankind;

Recommend further that Digital Earth be created in a way that also contributes to the exploration of, and scientific research on, global issues and the Earth system;

Declare the importance of Digital Earth in achieving global sustainable development;

Call for adequate investments and strong support in scientific research and development, education and training, capacity building as well as information and technology infrastructures, with emphasis, inter alia, on global systematic observation and modeling, communication networks, database development, and issues associated with interoperability of geo-spatial data;

Further call for close cooperation and collaboration between governments, public and private sectors, non-governmental organizations, and international organizations and institutions, so as to ensure equity in distribution of benefits derived from the use of Digital Earth in developed and developing economies;

Agree that, as a follow-up to the first International Symposium on Digital Earth held in Beijing, the International Symposium on Digital Earth should continue to be organized by interested countries or organizations biannually, on a rotational basis. 